\title{
Avaliação de impacto do programa de aquisição de alimentos modalidade doação simultânea em Ponte Nova- MG
}

\author{
Evaluation impact of food acquisition program buy direct mode in municipality of \\ Ponte Nova, Minas Gerais State \\ Cínthia Lopes Saliba Libânio ${ }^{1}$ (D) Jader Fernandes Cirino ${ }^{1}$ (1) \\ ${ }^{1}$ Departamento de Economia, Programa de Pós-graduação, Universidade Federal de Viçosa (UFV), Viçosa (MG), Brasil. E-mail: \\ jader.cirino@ufv.br; cinthia.saliba@ufv.br
} Como citar: Cirino, J. F. \& Libânio, C. L. S. (2020). Avaliação de impacto do programa de aquisição de alimentos modalidade doação
simultânea em Ponte Nova-MG. Revista de Economia e Sociologia Rural, 58(2), e195705. https://doi.org/10.1590/18069479.2020.195705

Resumo: O estudo analisa os impactos do PAA-DS sobre a renda mensal dos agricultores e o número de trabalhadores na atividade agrícola para o município mineiro de Ponte Nova em 2015. O objetivo é quantificar de que forma o programa estaria contribuindo para a melhoria do padrão de vida do agricultor e da sua família. Para tanto, utilizou-se o Propensity Score Matching que permite obter o efeito do programa sobre os tratados (beneficiários). Os resultados apontaram que, embora a renda não tenha sido estatisticamente diferente para os dois grupos, o fato de o número de trabalhadores envolvidos na produção ser maior estaticamente para os beneficiários, apoiado pelos resultados da análise descritiva de aumento das vendas, melhores preços e classificação satisfatória do PAA-DS para os beneficiários, mostra que o programa proporcionou melhores resultados para esse grupo em comparação aos não beneficiários. Dessa forma, conclui-se que, para o município, o programa está em consonância com o seu objetivo de fortalecimento da agricultura familiar de forma a promover o desenvolvimento sustentável.

Palavras-chave: avaliação de impacto, programa de aquisição de alimentos, doação simultânea, Ponte Nova-MG.

\begin{abstract}
This work analyzes the impacts of PAA-DS on the farmers' monthly income and the number of workers involved in the agricultural activity in the municipality of Ponte Nova. The objective is to quantify how the program would contribute to improving the standard of living of the farmer and his family. Propensity Score Matching was used to obtain the effect of the program. The results pointed out that although the income was not statistically different for the two groups, the fact that the number of workers involved in production was higher statically for the beneficiaries, supported by the results of the descriptive analysis increase in sales, better prices and satisfactory classification of the PAA-DS for the beneficiaries. Therefore these factors indicate that the program provide better results for this group compared to non-beneficiaries. Thus, it is concluded for the municipality, that this program is in line with its goal of strengthening family agriculture in order to promote sustainable development.
\end{abstract}

Keywords: impact evaluation, food acquisition program, simultaneous donation, Ponte Nova-MG.

\section{Introdução}

O Programa de Aquisição de Alimentos (PAA) foi criado em 2003 pelo governo federal como uma ação para colaborar com o enfrentamento da fome e da pobreza no Brasil e, ao mesmo tempo, fortalecer a agricultura familiar (Brasil, 2018). Sobre esse último aspecto, Bebbington et al. (2008) destacam que o PAA, assim como outras políticas públicas para tal 
segmento, decorreu da organização representativa do grupo de agricultores familiares, colocando em evidência suas reivindicações para a sociedade ${ }^{1}$.

O PAA utiliza mecanismos de comercialização que favorecem a aquisição direta de produtos de agricultores familiares ou de suas organizações, estimulando os processos de agregação de valor à produção. Com isso, o PAA é classificado como um programa de apoio à comercialização e à distribuição dos produtos alimentícios fornecidos pelos agricultores familiares.

O PAA possui seis modalidades, incluindo a Compra Direta com Doação Simultânea (PAA-DS), a qual será o objeto deste trabalho. Essa modalidade é responsável pela doação de produtos adquiridos da agricultura familiar a pessoas em situação de insegurança alimentar e nutricional. Segundo Oliveira (2011), essa modalidade apresenta significativa importância para a política nacional de segurança alimentar e nutricional e de estímulo à produção agrícola de nível local, pois engloba aqueles agricultores que enfrentam problemas com a comercialização de seus produtos, como também instituições que recebem esses alimentos em forma de doação. Além disso, focaliza suas ações nos locais onde a fome e a insegurança alimentar acontecem.

Em relação a estudos (Lopes \& Almeida, 2012; Agapto et al., 2012; Santos et al., 2012; Almeida et al., 2010; Cyntrão 2008; Doretto \& Michellon, 2007; Rocha et al., 2007; Delgado et al., 2005) que analisam a execução do PAA, em linha gerais, eles apontam que o programa tem contribuído para a formação de mercado consumidor para os agricultores familiares, propiciando para eles melhores preços, diminuição da dependência de atravessadores, aumento da quantidade e qualidade da produção e geração de renda no campo. Entretanto, os trabalhos também apontam falhas no programa como atrasos nos prazos de entrega e no cronograma de desembolsos, assim como a necessidade de gestão mais eficiente dos projetos desde a sua elaboração até a sua consecução.

Ainda sobre o PAA, Grisa et al. (2017) destacaram que o programa apresentou trajetória ascendente em termos de recursos financeiros e agricultores atendidos no período 2003-2012, sendo que, a partir de 2013, em função do aumento das regras formais e dos documentos exigidos, assim como da rigidez na fiscalização, a execução orçamentária do PAA diminuiu pela metade em 2015. Os autores ainda ressaltam que o declínio do programa ocorreu principalmente na modalidade Compra com Doação Simultânea, a qual foi objeto de maior controle e investigação.

Apesar da existência de muitos estudos que procuram analisar a execução do PAA nos estados e municípios brasileiros, a maior parte dessas análises utilizam metodologias qualitativas ou apenas análises descritivas. No entanto, ainda são incipientes os trabalhos de avaliação de impacto do programa com metodologias quantitativas mais robustas como os de Magalhães \& Soares (2007), Oliveira (2011) e Sobreira (2014).

Magalhães \& Soares (2007) analisaram o impacto da modalidade PAA-Leite sobre o preço, a produção e a renda da pecuária leiteira nos Estados da Bahia, Ceará Minas Gerais, Paraíba, Pernambuco, Piauí, Rio Grande do Norte e Sergipe por meio de regressões de séries temporais de oferta e demanda de leite. Já Oliveira (2011) avaliou o impacto dessa mesma modalidade do PAA para o município de Quixeramobim, Ceará, por meio de testes estatísticos de diferenças de média entre a renda das atividades agropecuárias dos beneficiários e não beneficiários do programa. Por fim, Sobreira (2014) estudou como o PAA impactou a produtividade, a geração de emprego, a renda e o capital social na atividade de apicultura do Estado do Ceará, utilizando o procedimento de Propensity Score Matching (PSM).

Nesse sentido, o presente trabalho propõe como problema de pesquisa a avaliação do Programa de Aquisição de Alimentos, modalidade Doação Simultânea (PAA-DS), no município de Ponte Nova, Minas Gerais, por meio do PSM. O foco é avaliar os impactos do programa sobre a renda dos agricultores beneficiários em 2015, assim como no número de trabalhadores envolvidos na produção.

O município de Ponte Nova está localizado na mesorregião Zona da Mata do Estado de Minas Gerais. Segundo Simão (2014), o expressivo êxodo rural dessa mesorregião advém principalmente de agricultores rurais classificados como tradicionais, cuja produção está

${ }^{1}$ A dinâmica de criação e implementação de políticas públicas no Brasil e na América Latina voltadas para o campo é analisada por Biekart (2005), Silva (2002) e Reardon et al. (2001). 
basicamente focada no atendimento das demandas locais. Isso evidencia que questões relativas à soberania alimentar e àquelas inerentes à permanência do pequeno agricultor no campo merecem atenção especial dos gestores públicos nessa localidade, uma vez que a região já está classificada como de risco à insegurança alimentar, aliada à crescente emigração de seus produtores rurais.

Nesse sentido, considerando apenas a modalidade Doação Simultânea, entre as doze mesorregiões em que se divide Minas Gerais, a Zona da Mata é a terceira com maior número de agricultores familiares que acessaram o PAA, perdendo apenas para sul/sudoeste de Minas e norte de Minas, no período de 2011 a 2015. Dentro da mesorregião da Zona da Mata, a microrregião de Ponte Nova é a segunda região com maior número de agricultores familiares beneficiados com o PAA no mesmo período, sendo que, desses agricultores, $52 \%$ tinham as suas propriedades localizadas no município de Ponte Nova (Secretaria de Avaliação e Gestão da Informação, 2018).

A hipótese do trabalho é que o programa, em consonância com o seu objetivo de fortalecimento da agricultura familiar e com as evidências de estudos para outras localidades, tenha gerado, em 2015, impacto positivo sobre a renda e o número de trabalhadores envolvidos nas atividades dos agricultores familiares beneficiários no município mineiro de Ponte Nova.

Dessa forma, o objetivo geral do trabalho é avaliar o impacto do PAA-DS no município de Ponte Nova, Minas Gerais, em 2015. Quanto aos objetivos específicos, tem-se: a) quantificar o impacto do programa em termos de renda e número de trabalhadores envolvidos nas atividades dos agricultores familiares beneficiados; b) caracterizar os agricultores entrevistados de acordo com variáveis socioeconômicas e aspectos relacionados à participação e avaliação do PAA-DS, separando-os em beneficiários e não beneficiários do programa; e c) analisar os fatores que influenciam a probabilidade de os agricultores participarem do PAA-DS.

O estudo está organizado em cinco partes, além desta introdução. No referencial teórico, apresenta-se breve discussão sobre a avaliação de políticas públicas. Na metodologia, tem-se os procedimentos utilizados para quantificar os impactos do PAA-DS no contexto proposto, com destaque para o procedimento do PSM, além da apresentação da fonte de dados. Nos resultados e discussão, apresenta-se análise descritiva dos dados, além das estimativas dos impactos do PAA-DS sobre as variáveis de resultado de interesse. Por fim, as conclusões apontam os principais desdobramentos e limitações do trabalho, assim como sugestões para estudos futuros.

\section{Referencial teórico: avaliação de políticas públicas}

As políticas públicas explicitam as diretrizes estratégicas do Estado em atividades diretas de produção de bens e serviços do próprio Estado, além de ações de regulação de outros agentes econômicos, assistindo ao bem comum. Depois de planejadas e formuladas, as políticas públicas dividem-se em planos, programas, projetos, bases de dados ou sistemas de informação e pesquisa. Quando postas em ação, são implementadas, estando sujeitas a sistemas de acompanhamento e avaliação (Bernardoni et al., 2008).

Segundo a ONU (Organização das Nações Unidas, 2009, p. 8), a avaliação pode ser conceituada como "uma apreciação rigorosa e independente das atividades concluídas ou em andamento para determinar até que ponto elas estão a alcançar os objetivos estabelecidos".

Diferentes métodos, modelos e técnicas são utilizados na pesquisa de avaliação de políticas e programas públicos, sendo essa última classificada segundo vários critérios.

Analisando o momento em que se realiza, a avaliação pode ser classificada como ex-ante, ou seja, realizada antes do início da operação. Esse tipo de análise permite estimar tanto os custos quanto os benefícios (ou impactos), fornecendo informações necessárias à implantação ou não do programa. De posse dessas últimas, é possível priorizar projetos e identificar a melhor alternativa para se obter os resultados. Já a avaliação ex-post pode ser realizada tanto durante o processo operacional quanto ao final da política ou programa, tendo a função de decidir pela continuação, reprogramação ou finalização. Além disso, serve como marco referencial para a decisão de se criar ou não programas similares (Cohen \& Martínez, 2006). 
Referente ao tipo de problema a ser solucionado, podem ser classificadas mais duas formas de avaliação: processos e impacto. A primeira está relacionada, sobretudo, à eficácia do programa, averiguando as disparidades entre as metas atingidas e planejadas, além da adequação entre os meios utilizados na implementação e os objetivos definidos originalmente. Já a avaliação de impacto (ou resultado) tem como base o critério de efetividade, em que se verificam mudanças nas condições dos beneficiários sob as óticas das pesquisas quantitativas e qualitativas (Cotta, 1998).

Quanto à caracterização do presente estudo, este é classificado quanto ao momento em que se realiza como ex-post e quanto ao tipo de problema como de impacto. Isso porque é analisado o impacto sobre a renda e o número de trabalhadores envolvidos nas atividades dos agricultores familiares beneficiados pelo PAA-DS em 2015, sendo que tal programa iniciou-se em 2003.

A avaliação de programa (e política pública) deve ser entendida como importante ferramenta de avanço no processo de tomada de decisão, permitindo aos governantes possuir melhores informações que posteriormente podem ser utilizadas para melhorar a concepção de um programa e sua implementação (Ala-harja \& Helgason, 2000).

Por fim, ressalta-se que, no campo da avaliação no Brasil, há dificuldades relacionadas à falta de dados ou registros de informações para o acompanhamento dos programas e políticas sociais. Dessa maneira, para a efetividade da avaliação é fundamental a existência de dados confiáveis gerados por órgãos e agências responsáveis ou ainda por pesquisas como as do presente trabalho.

\section{Metodologia: avaliação de impacto para os agricultores beneficiários do PAA-DS em Ponte Nova, MG}

Nessa seção, tem-se a metodologia para a avaliação de impacto do PAA- DS a fim de verificar possível mudança na renda e no número de trabalhadores envolvidos na atividade produtiva dos agricultores beneficiários do programa. Seguindo trabalhos que avaliaram impactos e efeitos de programas sociais (Magalhães et al., 2006; Resende \& Oliveira, 2008; Duarte et al., 2009; Maia et al., 2013; Sobreira, 2014), o Propensity Score Matching (PSM) foi a técnica escolhida.

Para utilizar a referida técnica, o primeiro passo é calcular as probabilidades de os agricultores participarem do PAA-DS por meio do modelo de regressão logística (Quadro 1).

Destaca-se que a escolha das variáveis do Quadro 1 foi embasada nos trabalhos de Sobreira (2014), Maia et al. (2013) e Magalhães et al. (2006).

Quadro 1 - Variáveis do modelo logit utilizado para a avaliação de impacto do PAA-DS sobre os agricultores beneficiários no município de Ponte Nova, MG, 2015

\begin{tabular}{|c|c|c|}
\hline Variáveis & Descrição & Classificação \\
\hline Participação no PAA-DS & $\begin{array}{c}\text { Se o agricultor participou do PAA-DS em 2015. Variável } \\
\text { dependente do modelo logit. }\end{array}$ & $\begin{array}{c}\text { Qualitativa } \\
\text { Sim }=1, \text { Não=0 }\end{array}$ \\
\hline Idade & Anos de idade. & Quantitativa \\
\hline Escolaridade & Grau de instrução dos agricultores medido por anos de estudo. & Quantitativa \\
\hline Casado & $\begin{array}{l}\text { Referente ao estado civil do produtor(a). Valor igual a } 1 \text { se } \\
\text { casado(a) e } 0 \text { para os demais estados civis. }\end{array}$ & $\begin{array}{c}\text { Qualitativa } \\
\text { Casado=1 } \\
\text { Solteiro, Viúvo, } \\
\text { divorciado=0 }\end{array}$ \\
\hline $\begin{array}{l}\text { Proprietário da terra } \\
\text { onde produz }\end{array}$ & $\begin{array}{l}\text { Se o produtor é dono da terra a variável terá valor 1, caso } \\
\text { contrário, valor } 0 .\end{array}$ & $\begin{array}{c}\text { Qualitativa } \\
\text { Sim=1, Não=0 }\end{array}$ \\
\hline $\begin{array}{l}\text { Tamanho da } \\
\text { propriedade }\end{array}$ & Área total da propriedade rural em hectares (ha). & Quantitativa \\
\hline $\begin{array}{l}\text { Comercializa por conta } \\
\text { própria }\end{array}$ & $\begin{array}{l}\text { Se o produtor comercializa sua produção por conta própria ou } \\
\text { se realiza parcerias para isso. }\end{array}$ & $\begin{array}{c}\text { Qualitativa } \\
\text { Sim=1, Não=0 }\end{array}$ \\
\hline Atividade Principal & $\begin{array}{l}\text { Se a atividade agrícola é a principal fonte de renda do } \\
\text { entrevistado. }\end{array}$ & $\begin{array}{c}\text { Qualitativa } \\
\text { Sim=1, Não=0 }\end{array}$ \\
\hline $\begin{array}{l}\text { Participação antes de } \\
\qquad 2015\end{array}$ & Se o agricultor já participou do PAA-DS antes de 2015. & $\begin{array}{c}\text { Qualitativa } \\
\text { Sim=1, Não=0 }\end{array}$ \\
\hline
\end{tabular}

Fonte: Elaboração própria. 
Em seguida, efetua-se o cálculo dos escores de propensão e o emparelhamento das probabilidades estimadas. Por fim, após o emparelhamento ou formação dos pares, é possível estimar o impacto do programa sobre o grupo dos tratados (agricultores beneficiados pelo PAA-DS). Destaca-se que o PSM apresenta duas características interessantes: i) correção da autosseleção de forma intuitiva ao criar pares de beneficiários e não beneficiários que possam ser comparáveis; e ii) evita problemas de multidimensionalidade por meio de escore que representa todas as variáveis importantes para a comparação dos grupos.

O impacto do PAA-DS sobre as variáveis escolhidas seria mais precisamente estimado pela diferença entre o resultado dos agricultores participantes na presença e na ausência do programa. Porém, não se pode observar ambos os resultados para o mesmo agricultor simultaneamente. Dada a impossibilidade dessa observação na prática, tomar o resultado médio dos agricultores não participantes do programa como uma aproximação torna-se uma alternativa, porém limitada, uma vez que os participantes e não participantes normalmente diferem mesmo na ausência de tratamento.

Especialmente no caso do PAA-DS, os agricultores familiares aptos a participarem do programa devem atender aos requisitos do artigo $3^{\circ}$ da Lei n. ${ }^{\circ} 11.326$ de 24 de julho de 2006, disponível em Brasil (2018), sendo a adesão ao programa voluntária. Dessa forma, não se pode pressupor a aleatoriedade desta seleção. Além disso, as características iniciais desses agricultores são importantes fatores que determinam seus resultados. Portanto, a escolha dos agricultores que constituem o grupo de controle deve considerar a presença de viés de seleção.

Para contornar o problema do viés de seleção, foi utilizado o Matching (Pareamento) conforme Magalhães et al. (2006), Maia et al. (2013) e Sobreira (2014). Sua ideia básica é encontrar em um grande grupo de não participantes, unidades que são semelhantes aos participantes em todas as características (observáveis) relevantes pré-tratamento - um vetor de variáveis $X-e$, assim, construir um grupo de controle que represente adequadamente 0 que aconteceria com os agricultores familiares participantes se eles não estivessem inscritos no programa.

A inclusão de grande número de variáveis em $X$, sejam elas contínuas ou bidimensionais, dificultaria a realização do matching. Para solucionar o problema, Rosenbaum \& Rubin (1983) sugerem que ao invés de parear as unidades com base em todo o vetor $X$, pode-se parear as unidades usando uma função de $X$ que resume toda a informação contida neste vetor. Trata-se de sumarizar as características observáveis de cada unidade em uma única variável, o propensity score (escore de propensão). Esta técnica de pareamento é chamada de PSM.

Rosenbaum \& Rubin (1983) definem o propensity score como a probabilidade condicional de se receber o tratamento dado um vetor de variáveis observáveis. Formalmente:

$P(D=1 \mid X)=P(X)=E(D / X)$

em que $D$ é uma variável binária que assume valor igual a 1 se o agricultor participou do programa PAA-DS em 2015 e 0, caso contrário, e X refere-se ao vetor de características observáveis que afetam a seleção para o programa.

Os agricultores participantes foram então combinados em função dessa probabilidade, o propensity score, com aqueles não participantes. Dessa forma, para este trabalho, a função $P(X)$ foi estimada a partir de um modelo logit em que a variável dependente é um indicador binário de participação do PAA-DS e as variáveis de controle são as características dos agricultores.

Quanto ao pareamento baseado no propensity score, esse depende de uma métrica pré- determinada, que define a proximidade do escore de propensão das unidades tratadas em relação ao escore de propensão das unidades não tratadas. Diferentes procedimentos podem ser adotados para a realização do pareamento, sendo que a técnica mais utilizada 
para tal fim é a do Pareamento ao Vizinho mais próximo (Nearestneighbor Matching). Essa consiste em parear cada unidade do grupo de tratamento a uma unidade do grupo de controle que tenha o propensity score mais próximo. O pareamento pode ser realizado com ou sem reposição. A escolha por reposição indica que uma mesma unidade do grupo de controle pode ser pareada com mais de uma unidade participante (Khandker et al., 2010). No presente estudo, assim como em Sobreira (2014), optou-se pelo pareamento sem reposição.

Após o emparelhamento ou formação dos pares, torna-se possível estimar o impacto do programa sobre o grupo dos tratados. Neste trabalho existem duas variáveis de interesse (renda e número de trabalhadores envolvidos no processo produtivo). A título de exemplo, supõe-se que a variável de interesse seja $R_{l i}$, que corresponde ao nível de renda do agricultor $i$ que recebe o tratamento, e $R_{0 i}$ é a mesma variável para o agricultor que não recebe o tratamento. Com base nessas informações, o efeito médio do tratamento sobre os tratados (ATT) pode ser dado por:

$A T T=E\left\{E\left\{R_{l i} \mid D_{i}=1, p\left(X_{i}\right)\right\}-E\left\{R_{0 i} \mid D_{i}=0, p\left(X_{i}\right)\right\} \mid D_{i}=1\right\}$

em que, conforme Becker \& Ichino (2002), o impacto do programa sobre a variável de interesse (R) é dado pela diferença das esperanças (E) calculada pela distribuição de ( $p(X i) \mid$ $D_{i}=1$ ) em que $R_{l i}$ e $R_{0 i}$ são os resultados potenciais dos dois grupos de comparação, respectivamente, tratados e não tratados.

As variáveis de resultado - Renda mensal total em reais (R) e Número de trabalhadores empregados (NT) - foram escolhidas a partir de Sobreira (2014), Maia et al. (2013) e Magalhães et al. (2006).

No que se refere à fonte dos dados, esses são primários, tendo sido obtidos com a aplicação de questionários semiestruturados ${ }^{2}$ junto aos agricultores beneficiários e não beneficiários do PAA-DS no município de Ponte Nova, MG (Figura 1).

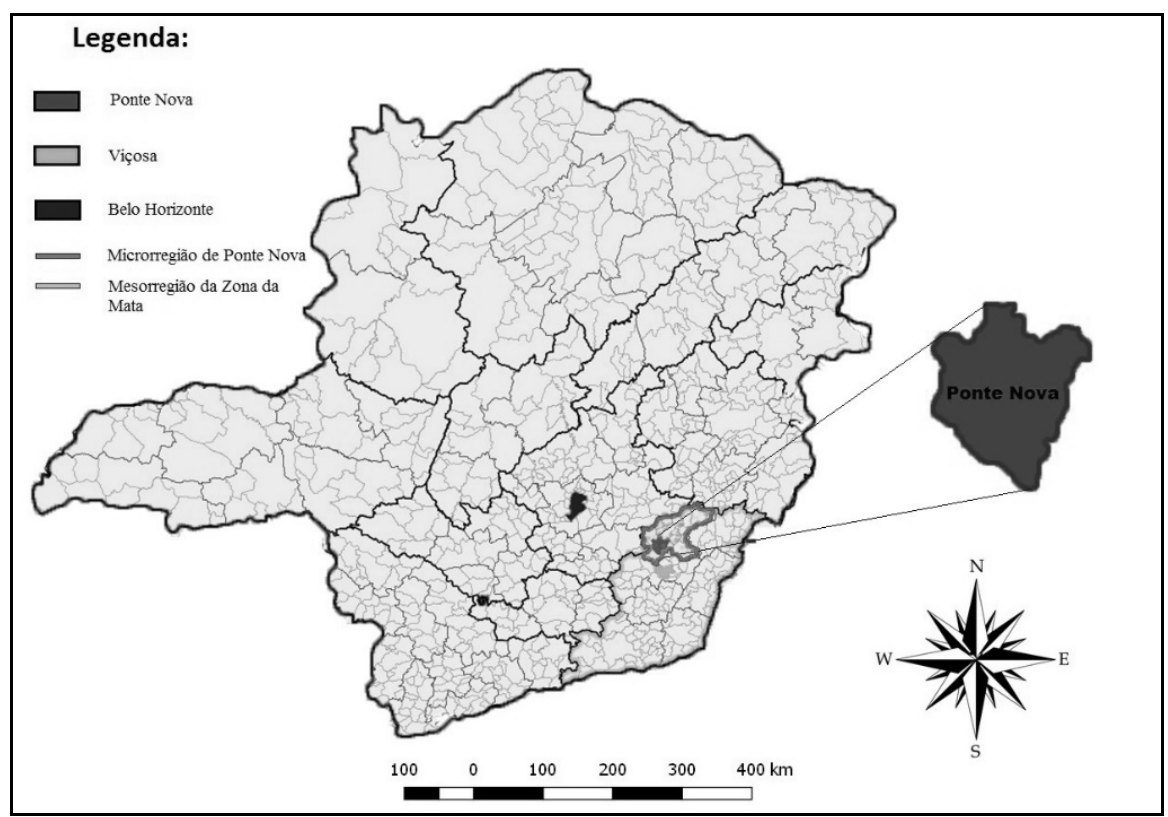

Figura 1- Recorte geográfico da pesquisa.Fonte: Elaborado pelos autores a partir de IBGE (Instituto Brasileiro de Geografia e Estatística, 2018).

${ }^{2}$ Questionário completo e maiores informações sobre a pesquisa de campo disponíveis em Libanio (2018). 
Segundo a Empresa de Assistência Técnica e Extensão Rural (EMATER) do município, a zona rural se divide em 36 comunidades distribuídas em três setores.

De acordo com a Secretaria Municipal de Desenvolvimento Rural (SEDRU) do município, somando-se os dois semestres de 2015, 58 agricultores forneceram alimentos pelo PAA-DS. Portanto, dada a dificuldade de acesso às residências dos agricultores, entende-se que a parcela da amostra composta por 48 agricultores beneficiados pelo programa em 2015 (grupo de tratados) é representativa da população em estudo. Por outro lado, para atender ao objetivo de avaliar o impacto para os beneficiários do PAA-DS por meio do PSM, a outra parte da amostra foi composta por 47 dos agricultores atendidos pela EMATER, mas que não foram beneficiários do programa (grupo de controle), totalizando assim 95 questionários.

Os dados foram coletados entre janeiro e abril de 2017. Os questionários foram aplicados nas casas dos agricultores familiares participantes e não participantes do PAA-DS, os quais moram na zona rural do município em questão.

A condução da pesquisa de campo foi feita pelos autores do presente artigo em parceria com a Empresa Júnior de Economia e Serviços de Consultoria (EJESC) do Departamento de Economia da Universidade Federal de Viçosa. Importante destacar que o estudo foi aprovado pelo Comitê de Ética em Pesquisa com Seres Humanos (CEP) da Universidade Federal de Viçosa por meio do parecer número 2.313.025.

Destaca-se que, durante a coleta de dados, buscou-se entrevistar o principal membro da família responsável pela atividade agrícola e, no caso dos beneficiários, entrevistou-se o indivíduo que possuía o cadastro do programa em seu nome.

\section{Resultados e discussão}

Nesta seção apresenta-se, inicialmente, análise descritiva das variáveis socioeconômicas, de produção e aspectos relacionados à participação e avaliação do PAADS para os agricultores entrevistados, separando-os em beneficiários e não beneficiários do programa. Em seguida, tem-se os resultados dos determinantes da probabilidade de os agricultores participarem do PAA-DS em Ponte Nova no ano de 2015. Por fim, apresenta-se a avaliação de impacto sobre a renda e o número de trabalhadores envolvidos na atividade produtiva dos agricultores beneficiários por meio do PSM.

Começando pela análise descritiva, no que tange ao gênero, entre os beneficiários, 54\% dos entrevistados eram homens e $46 \%$ mulheres, sendo tais valores respectivamente de $74 \%$ e $26 \%$ para os não beneficiários. Como no primeiro grupo, a participação das mulheres foi mais expressiva, o programa parece contribuir para a participação feminina na atividade agrícola em Ponte Nova.

Quanto à idade dos agricultores entrevistados, existe predominância de produtores na idade entre 50 e 65 anos, tanto para beneficiários como para não beneficiários, com 41,67\% e 40,43\%, respectivamente. Destaca-se ainda que a distribuição dos agricultores nas demais faixas etárias mostrou-se bem próxima para os dois grupos.

Em relação à escolaridade, também não se observou diferença importante entre o grupo de beneficiários e não beneficiários, uma vez que ambos apresentaram, em média, 6 anos de estudo, ou seja, ensino fundamental incompleto. Outros estudos, como os de Rossi (2012), Sobreira (2014), Oliveira (2015) e Bastos (2017) também encontraram resultados similares, indicando que, em geral, a agricultura se configura como atividade cujos produtores possuem baixo grau de instrução.

No que se refere ao estado civil, a maioria dos agricultores declararam ser casados, sendo que a proporção de casados para os dois grupos foi a mesma (77\%).

Em relação à propriedade da terra, a grande maioria dos agricultores de Ponte Nova entrevistados são proprietários da terra onde produzem, sendo a proporção de respostas que se enquadraram nesta categoria de 68,75\% e 78,72\%, respectivamente, para beneficiários e não beneficiários do PAA-DS.

No que tange ao tamanho da propriedade utilizada para a produção agrícola, a maioria dos agricultores entrevistados, tanto beneficiários (67\%) quanto não beneficiários (64\%), produzem em áreas com menos de 10 hectares. Destaca-se também que para os dois 
grupos, a maioria dos entrevistados tem na atividade agrícola a sua principal fonte de renda (94\% e 92\%, respectivamente, para beneficiários e não beneficiários do programa) e comercializam a maior parte da produção agrícola por conta própria (87,5\% dos beneficiários e 91,5\% dos não beneficiários).

As duas últimas variáveis socioeconômicas a serem apresentadas são as variáveis de resultado do PSM do presente estudo que são: renda mensal do agricultor e número de trabalhadores envolvidos na atividade agrícola.

Quanto à renda mensal, a maior parte dos beneficiários $(56,25 \%)$ e dos não beneficiários $(57,45 \%)$ responderam que possuíam em 2015 rendimento mensal entre um e três salários mínimos ${ }^{3}$. A segunda opção mais escolhida pelos agricultores entrevistados é a de renda mensal de até um salário mínimo, sendo que 29,17\% dos beneficiários e 36,17\% dos não beneficiários se enquadraram nessa opção.

A fim de verificar a existência ou não de diferença estatística nos rendimentos médios mensais dos dois grupos estudados, procedeu-se a um teste de média para a referida variável ${ }^{4}$. Na Tabela 1, o teste U de Mann-Whitney indica que não existe diferença significativa na renda média mensal entre beneficiários e não beneficiários do PAA-DS em Ponte Nova ${ }^{5}$. Tal resultado é um primeiro indício de que o referido programa parece não ter impactado significativamente a renda mensal dos seus beneficiários em comparação a dos não beneficiários.

Tabela 1 - Comparação das médias de renda mensal entre beneficiários e não beneficiários do PAA-DS, Ponte Nova, MG, 2015.

\begin{tabular}{ccccccc} 
PAA-DS & Média & Mediana & D-Padrão & E-Padrão & Mínimo & Máximo \\
Beneficiário & 2010,71 & 1874 & 1271,113 & 183,469 & 937 & 7496 \\
Não Beneficiário & 1903,91 & 1874 & 1698,805 & 247,796 & 937 & 9370 \\
Teste & Statistic & $\mathrm{N}$ & Sig. & & & \\
U de Mann-Whitney & $-0,065$ & 95 & 0,287 & & & \\
\hline
\end{tabular}

Fonte: Resultados da pesquisa.

Em relação ao número de trabalhadores envolvidos na atividade agrícola, a maioria dos beneficiários (56,25\%) utilizou em 2015 duas pessoas na atividade agrícola enquanto que, para os não beneficiários, a maioria dos entrevistados $(57,45 \%)$ necessitou de apenas uma pessoa para realizar a atividade.

O teste $U$ de Mann-Whitney para comparação das médias dos trabalhadores envolvidos na atividade agrícola dos beneficiários e não beneficiários do PAA-DS sugere que existe diferença significativamente estatística para a média dos dois grupos analisados, indicando que o primeiro grupo utilizava em 2015, comparativamente, mais trabalhadores do que o segundo grupo (Tabela 2 ).

Tabela 2 - Comparação das médias do número de trabalhadores envolvidos na atividade produtiva entre beneficiários e não beneficiários do PAA-DS em Ponte Nova, MG, 2015.

$\begin{array}{ccccccc}\text { PAA-DS } & \text { Média } & \text { Mediana } & \text { D-Padrão } & \text { E-Padrão } & \text { Mínimo } & \text { Máximo } \\ \text { Beneficiário } & 2,29 & 2 & 1,166 & 0,168 & 1 & 6 \\ \text { Não Beneficiário } & 1,72 & 1 & 1,280 & 0,187 & 1 & 7 \\ \text { Teste } & \text { Statistic } & \mathrm{N} & \text { Sig. } & & & \\ \text { U de Mann-Whitney } & -3,619 & 95 & 0,000 & & & \end{array}$

Fonte: Resultados da pesquisa.

\footnotetext{
${ }^{3}$ Quando da realização da pesquisa, foi considerado o salário mínimo em vigor no ano de 2017 (R $\left.\$ 937,00\right)$. ${ }^{4}$ Para transformar a variável renda que foi obtida no questionário por faixas de renda em variável contínua, multiplicou-se o ponto médio da faixa escolhida pelo entrevistado pelo valor do salário mínimo considerado na pesquisa.

${ }^{5} \mathrm{O}$ teste $\mathrm{U}$ de Mann-Whitney compara se a média entre dois grupos é igual, sendo a hipótese nula do teste, médias diferentes. Maiores detalhes em Sobreira (2014).
} 
Ainda sobre a atividade agrícola, os entrevistados apontaram as dificuldades encontradas na comercialização da produção em 2015. Tanto entre os beneficiários como entre os não beneficiários, a maioria das respostas foi "não teve dificuldade" e "preço baixo", embora tais valores tenham sido de $39,58 \%$ e $29,17 \%$, para o primeiro grupo, e de $44,68 \%$ e $42,55 \%$ para o segundo grupo, respectivamente. Essa diferença indica que o programa contribuiu para a sustentação e melhoria dos preços em Ponte Nova em 2015, uma vez que os beneficiários estavam comparativamente mais satisfeitos do que os não beneficiários em relação aos preços dos produtos comercializados, assim como verificado em outros trabalhos (Almeida et al., 2010; Agapto et al., 2012; Rossi, 2012; Dias \& Rocha, 2014; Sobreira, 2014; Oliveira, 2015).

Antes de apresentar os dados referentes à participação e avaliação do PAA-DS por parte dos agricultores entrevistados, torna-se interessante mostrar informações referentes ao acesso a outros programas governamentais por parte dos entrevistados. Destaca-se que todos os beneficiários do PAA-DS participam também de outros programas do governo, enquanto $63,83 \%$ dos não beneficiários não fazem parte de nenhum outro programa governamental. Camargo et al. (2013) afirmam que a partir do momento em que os grupos têm acesso aos programas de políticas públicas, eles passam a conhecer os procedimentos e exigências necessárias para participarem de tais programas, o que facilita a sua inserção.

Outro ponto a ressaltar é que a maior parte dos beneficiários do PAA-DS fornece produtos ao PNAE, 66,67\%, ao passo que, entre os não beneficiários, apenas 2,13\% também comercializam a produção com esse programa. Esse resultado indica que a inserção no PAA impulsiona a participação no PNAE, principalmente após a criação da lei 11.947/09 (Brasil, 2018), a qual estabeleceu que do total dos recursos financeiros repassados pelo Fundo Nacional de Desenvolvimento da Educação (FNDE), no âmbito do PNAE, no mínimo 30\% deveriam ser utilizados na aquisição de gêneros alimentícios diretamente da agricultura familiar e do empreendedor familiar rural ou de suas organizações.

Passando para a discussão acerca da participação e da avaliação do PAA-DS por parte dos agricultores entrevistados, apresentam-se, inicialmente, os dados para os beneficiários do programa. Tratando-se da participação em anos anteriores a 2015, 81,25\% dos beneficiários entrevistados já participaram do PAA-DS anteriormente e somente 18,75\% nunca haviam participado. Esse resultado indica que o agricultor que participa uma vez do programa estará, em sua maioria, disposto a participar novamente. Isso ocorre pelo fato de o agricultor estar satisfeito com o programa (no presente estudo, 64,6\% e 35,4\% dos beneficiários do programa o classificaram como "Bom" e “Ótimo", respectivamente). Resultados similares foram encontrados por Doretto \& Michellon (2007) no Paraná e Agapto et al. (2012) em São Paulo. Destaca-se também que, uma vez familiarizado com as rotinas e os processos necessários para participar do programa, o agricultor tende a fazê-lo novamente.

A maior parte dos beneficiários que já acessou o PAA-DS anteriormente acessou apenas uma vez antes de 2015. No caso do presente estudo, considera-se o acesso durante um ano como uma vez, mesmo que esse acesso seja renovado a cada semestre (Figura 2).

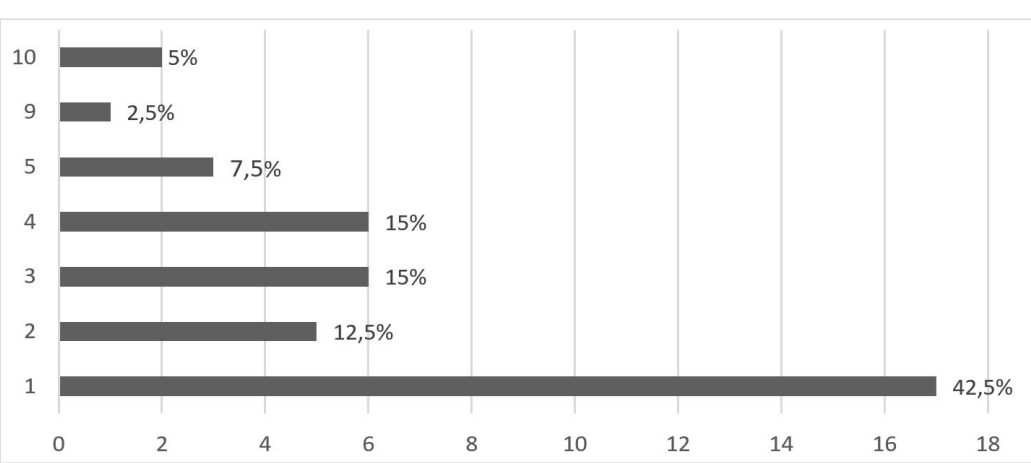

Figura 2- Distribuição dos beneficiários do PAA-DS, segundo o número de acessos anteriores ao ano de 2015, Ponte Nova, MG. Fonte: Resultados da pesquisa. 
Os beneficiários entrevistados foram questionados sobre como eles ficaram sabendo do PAA-DS, sendo que a Emater local é a principal responsável pelo acesso às informações sobre o programa, já que $54,17 \%$ dos respondentes souberam do PAA-DS por meio dessa instituição. Bastos (2017) também destaca o papel da Emater na disseminação das informações sobre programas, editais e projetos voltados para os agricultores familiares de Coimbra-MG.

Além de como classificam o programa, os beneficiários também disseram qual o motivo para participarem do PAA-DS, sendo a "Facilidade em vender" e os "Preços melhores do que os do mercado", os motivos citados por $72,92 \%$ e $14,58 \%$ dos beneficiários, respectivamente (Figura 3). Resultados semelhantes foram encontrados por Sobreira (2014) no Ceará e por Rossi (2012) entre agricultores do município de São Carlos, no Estado de São Paulo.

Apesar de bem avaliado por seus beneficiários, questionou-se qual seria a principal dificuldade ou barreira para a participação no PAA-DS, uma vez que nem todos os agricultores conseguem se tornar beneficiários de tal programa.

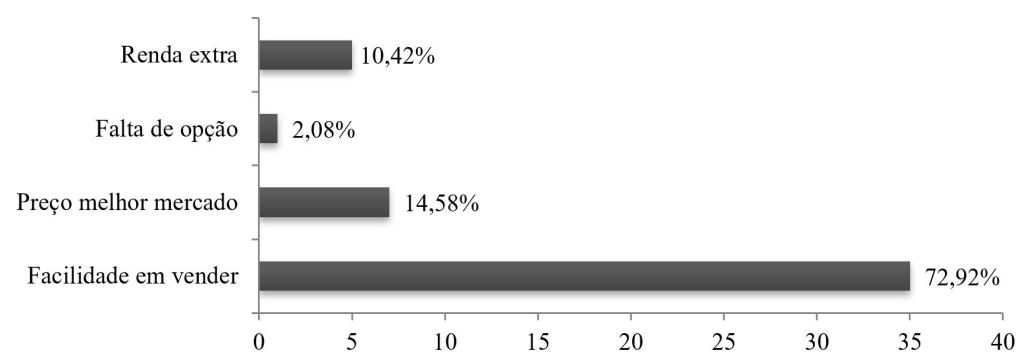

Figura 3 - Distribuição dos beneficiários do PAA-DS, segundo o motivo para participar do programa em Ponte Nova, MG, 2015. Fonte: Resultados da pesquisa.

Como retratado na Figura 4, a maioria dos beneficiários, 52\%, "Não tiveram dificuldades para participar". Em contrapartida, 18,75\% disseram ter tido "Dificuldades com a documentação exigida", o que muitas vezes é visto pelos agricultores como um excesso de burocracia. Essa questão vai ao encontro do aumento das regras formais e documentos exigidos, assim como maior rigidez na fiscalização das alterações normativas que levaram o PAA a diminuir a quantidade de recursos executados e agricultores atendidos a partir de 2013, conforme apontado por Grisa et al. (2017). "A quantidade insuficiente da produção" foi a segunda dificuldade mais citada pelos beneficiários (12,5\%), ressaltando a necessidade de planejamento da produção para atender adequadamente às demandas do PAA-DS, em consonância com Cirino \& Silva (2017).

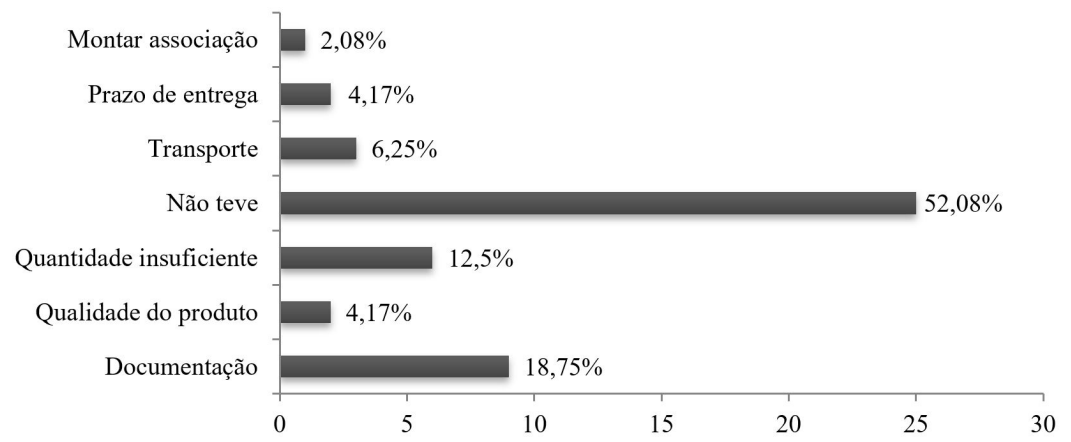

Figura 4 - Distribuição dos beneficiários do PAA-DS, segundo a principal dificuldade para participar do programa, Ponte Nova, MG, 2015. Fonte: Resultados da pesquisa.

Além das dificuldades para participar, os beneficiários do PAA-DS disseram quais melhorias poderiam ser feitas no programa. A Figura 5 mostra que $23 \%$ dos entrevistados responderam que "Nada precisava ser melhorado", já que o programa os atendia bem. Para 
$27 \%$ dos beneficiários entrevistados, o programa poderia "Aumentar a quantidade de produto comprada" de cada agricultor, o que implicaria aumento no valor repassado a cada família. Outra melhoria sugerida foi nas "Organizações das entregas" (18,75\%), uma vez que os respondentes disseram que a má organização faz com que as entregas demorem demasiadamente, atrapalhando as entregas que os agricultores possuem no dia para outros compradores. "Melhoria no preço dos produtos" foi citada apenas por 4,17\%, o que revela que a maioria dos beneficiários está satisfeita com o preço pago pelo programa.

Em relação ao aumento da produção, os beneficiários responderam que a participação no PAA-DS elevou a produção desses, evidenciando a capacidade do programa para gerar aumentos na produção agrícola dos produtores rurais (Delgado et al., 2005; Rocha et al., 2007; Martins \& Cavalcanti, 2007; Santos et al., 2012; Oliveira, 2015). Tal situação é reforçada pelo fato de que os produtores, ao aderirem ao PAA, não deixaram de atender às demandas que já possuíam. O fato de aumentarem a produção faz com que eles consigam atender os clientes fora do programa e à demanda municipal gerada pelo PAA-DS. Sendo assim, 83,33\% dos beneficiários entrevistados responderam que não deixaram de atender a ninguém após a participação no programa.

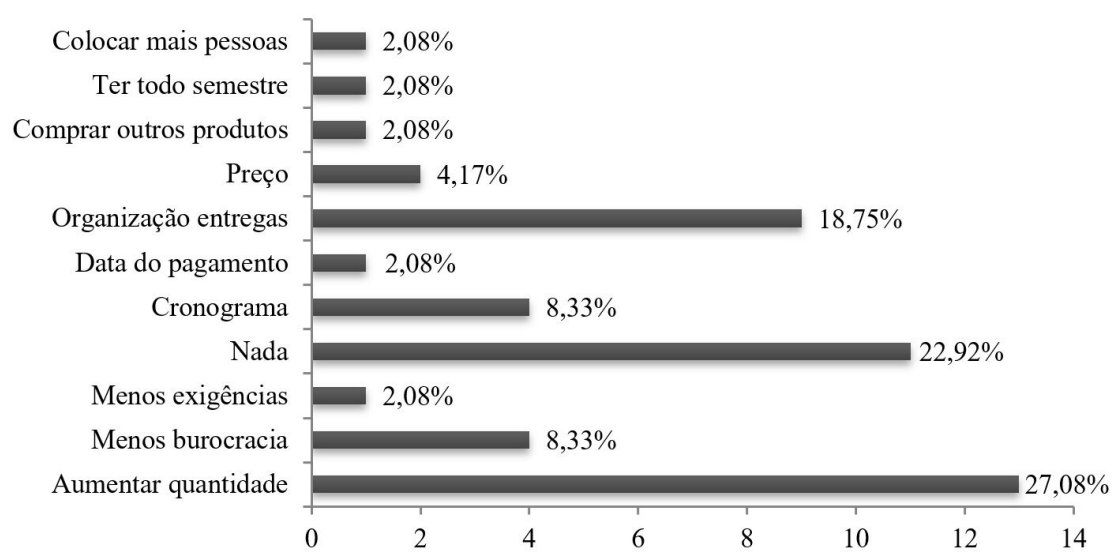

Figura 5 - Distribuição dos beneficiários do PAA-DS, segundo as melhorias necessárias ao programa, Ponte Nova, MG, 2015. Fonte: Resultados da pesquisa.

Por fim, para os não beneficiários do PAA-DS, procurou-se saber os motivos para não terem participado do programa em 2015. A Figura 6 revela que 36\% dos agricultores pertencentes ao grupo controle não participaram porque "Não tiveram oportunidade", 19\% não participaram porque "Não sabiam que podiam", uma vez que não tiveram informações claras sobre como participar e o que seria necessário para a participação e outros $19 \%$ não participaram porque "Não tiveram interesse". O restante não participou devido ao "Excesso de burocracia" (15\%) ou por achar o "Preço praticado pelo mercado melhor" do que o preço pago pelo programa (11\%).

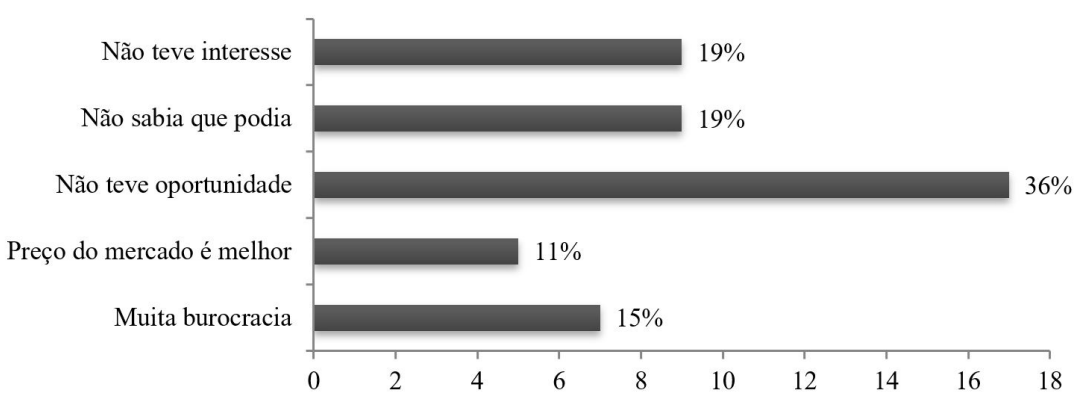

Figura 6 - Distribuição dos não beneficiários do PAA-DS em Ponte Nova, MG, segundo o motivo de não ter participado do programa no ano de 2015. Fonte: Resultados da pesquisa. 
Tais resultados mostram que o PAA-DS poderia beneficiar número maior de agricultores caso fosse aumentada a quantidade de recursos financeiros e a divulgação do programa, ao mesmo tempo que a burocracia fosse reduzida. Ressalta-se que apenas $30 \%$ dos não beneficiários não demonstraram interesse em participar do PAA-DS ("Não teve interesse" e "Preço do mercado é melhor"), indicando que existe público potencial para ampliação do programa em Ponte Nova.

Para discutir as probabilidades de os agricultores participarem do PAA-DS, apresentam-se, inicialmente, os critérios utilizados para avaliar a qualidade e o grau de ajustamento da regressão logística estimada, cujos principais são: porcentagem de casos corretamente explicados, Count $\mathrm{R}^{2}$ e estatística do quiquadrado significativa (Favero et al., 2014; Gujarati \& Porter, 2011). No presente estudo, o primeiro critério estabelece a porcentagem de agricultores que o modelo previu corretamente em cada um dos dois grupos, ou seja, aqueles que foram previstos como beneficiários e de fato são, valendo o mesmo para os não beneficiários. Nesse sentido, o modelo foi capaz de prever corretamente $88,92 \%$ das observações, indicando bom ajuste confirmado pelo Count $\mathrm{R}^{2}$, cujo valor de $88,4 \%$ representa o quociente entre o número de previsões corretamente explicadas e o número de observações totais do modelo. Quanto à estatística quiquadrado, ela foi estatisticamente significativa a 1\%, indicando que existe uma regressão entre a probabilidade de os agricultores participarem do PAA-DS e as variáveis explicativas consideradas.

A fim de analisar o papel de cada variável explicativa sobre a probabilidade de interesse, utilizou-se o efeito marginal, que indica o impacto, em pontos percentuais, da variável explicativa sobre a probabilidade em estudo, e a razão de chance, a qual indica a alteração na chance de ocorrência do evento de interesse ao se variar em uma unidade esta mesma variável (variáveis contínuas) ou em função da presença de determinada qualidade (variáveis binárias), mantidas as demais variáveis constantes. A significância dos coeficientes estimados pode ser verificada pelos valores da coluna $\mathrm{p}$-valor da Tabela 3.

Tabela 3- Determinantes da probabilidade de participação dos agricultores no PAA-DS em Ponte Nova, MG, 2015.

\begin{tabular}{|c|c|c|c|c|c|}
\hline Variável & Coeficiente & $\begin{array}{l}\text { Razões de } \\
\text { chance }\end{array}$ & Teste Z & P - Valor & Efeito Marginal \\
\hline Idade & $-0,033$ & 0,967 & -0.97 & 0.330 & $-0,0089$ \\
\hline Escolaridade & -0.199 & 0,820 & -1.72 & 0.085 & $-0,0471$ \\
\hline Casado & 2,100 & 8,169 & 1.76 & 0.078 & 0,4807 \\
\hline $\begin{array}{l}\text { Proprietário da terra onde } \\
\text { produz }\end{array}$ & -0.456 & 0,634 & -0.56 & 0.576 & $-0,1047$ \\
\hline Tamanho da propriedade & $-0,016$ & 0,984 & -0.62 & 0.538 & $-0,0038$ \\
\hline $\begin{array}{c}\text { Comercializa por conta } \\
\text { própria }\end{array}$ & $-2,514$ & 0,081 & -1.67 & 0.095 & $-0,3878$ \\
\hline Atividade Principal & $-1,581$ & 0,205 & -1.04 & 0.297 & $-0,2868$ \\
\hline Participação antes de 2015 & 6,039 & 419,62 & 4.33 & $0.000^{*}$ & 0,8794 \\
\hline Constante & 3,514 & 33,603 & 1.00 & 0.316 & - \\
\hline
\end{tabular}

Fonte: Resultados da pesquisa. *Estatisticamente significativa a 1\%.

Observa-se que, das oito variáveis explicativas analisadas, apenas a variável que indica participação no PAA-DS antes de 2015 foi significativa ao nível de significância de pelo menos 5\%. Dessa forma, os agricultores que participaram do programa em algum ano anterior a 2015 aumentaram em 87,94 pontos percentuais a probabilidade de participarem novamente. Em relação à razão de chances, ter participado alguma vez do PAA-DS aumenta 419 vezes a chance de o agricultor participar novamente. Observou-se pela análise 
descritiva que $39(81,25 \%)$ dos 48 agricultores beneficiários do PAA-DS em 2015 haviam participado do programa anteriormente, de forma que apenas $9(18,75 \%)$ agricultores desse grupo estavam participando pela primeira vez. Já entre os 47 não beneficiários entrevistados, apenas $3(6,38 \%)$ participaram do PAA-DS alguma vez antes de 2015 , sendo que $44(93,62 \%)$ desses agricultores nunca participaram do programa em questão. Essa diferença expressiva entre os dois grupos no que tange à tal variável justifica o alto poder de sua explicação dentro do modelo apresentado.

A explicação para que os agricultores continuem acessando ao PAA-DS, conforme já apresentada na análise descritiva, reside no fato de a maioria deles estar satisfeita com o programa, além de apontarem como bons os preços pagos pelo programa e a questão de ele criar um mercado para os produtos, facilitando a venda. Ademais, uma vez acostumado com os procedimentos necessários para participar do programa, o agricultor tende a continuar acessando-o.

Por outro lado, a expressiva parcela dos não beneficiários que nunca participaram do PAA-DS indica barreiras à entrada de novos beneficiários, as quais podem estar relacionadas à falta de conhecimento sobre a existência e o funcionamento do programa, assim como excesso de burocracia e exigências para acessar a política em questão. Aumentar o alcance das informações sobre o PAA-DS por meio de maior divulgação do programa entre os agricultores familiares que não participam e buscar auxiliar tais agricultores quanto à elaboração do projeto e documentação exigida contribuirá para a entrada de novos beneficiários.

Quanto às demais variáveis explicativas do modelo logit não terem sido significativas, acredita-se que tal situação deveu-se ao fato de que, de maneira geral e em termos médios, elas não apresentaram expressiva diferença entre beneficiários e não beneficiários do PAADS e, por isso, não foram importantes para explicar a probabilidade de participação em tal programa.

Na Tabela 4, é possível observar o impacto do PAA-DS para os agricultores beneficiários em relação às variáveis de interesse: renda mensal total em reais (renda) e número de trabalhadores envolvidos na atividade produtiva (trabalhadores).

Tabela 4 - Efeitos do tratamento sobre os tratados (ATT) para beneficiários do PAA-DS em Ponte Nova, MG, 2015.

\begin{tabular}{|c|c|c|c|c|c|}
\hline \multirow{2}{*}{ Variáveis de interesse } & \multicolumn{2}{|c|}{ Valores Médios } & \multirow{2}{*}{$\frac{\text { ATT }}{\text { Diferença }}$} & \multirow{2}{*}{$\begin{array}{l}\text { Desvio } \\
\text { padrão }\end{array}$} & \multirow{2}{*}{$\begin{array}{c}\text { Estatística- } \\
t\end{array}$} \\
\hline & Beneficiários & Não Beneficiários & & & \\
\hline Renda & $1.856,70$ & $1.752,54$ & 104,16 & 279,395 & 0,37 \\
\hline Trabalhadores & 2,22 & 1,41 & 0,81 & 0,338 & 2,41 \\
\hline $\begin{array}{l}\text { Procedimento } \\
\text { Bootstrap }\end{array}$ & & & $\begin{array}{l}\text { Desvio } \\
\text { padrão }\end{array}$ & Teste Z & P-valor \\
\hline Renda & $1.856,70$ & $1.752,54$ & 354.214 & 0.29 & 0.769 \\
\hline Trabalhadores & 2,22 & 1,41 & 0.415764 & 1.96 & 0.050 \\
\hline
\end{tabular}

Fonte: Resultados da pesquisa.

A segunda e a terceira colunas da Tabela 4 são os valores médios de cada variável de resposta resultante do pareamento do método do vizinho mais próximo, sendo que a segunda e a terceira linhas da quarta coluna representam a diferença entre tais valores médios para a renda e os trabalhadores, respectivamente. Essa diferença representa o ATT que indica os impactos do PAA-DS para os beneficiários do programa. A significância estatística desses impactos é apresentada na última coluna pela estatística-t e pelo p-valor do procedimento bootstrap.

Iniciando pela renda, tem-se que os beneficiários declararam ter renda mensal média $\mathrm{R} \$ 104,16$ superior à dos não beneficiários. Entretanto, de maneira contrária ao levantado pela hipótese do estudo, tanto pela estatística-t quanto pelo p-valor, essa diferença não foi 
estatisticamente significativa, o PSM indica não haver diferença para essa variável de resposta entre os dois grupos.

Sobre esse resultado, acredita-se que ele está mais associado a uma limitação dos dados do que ao fato de o programa não gerar impacto sobre a renda do agricultor. Isso porque, devido à dificuldade natural para levantar informações sobre a renda do entrevistado, o presente estudo utilizou faixas de renda mensal. Dessa forma, considerando a faixa mais citada para ambos os grupos, entre um ( $\$$ \$937) e três salários mínimos $(R \$ 2.811)$, sua amplitude é de $R \$ 1.874$, fato esse que pode ter mascarado o efeito do programa para os beneficiários em comparação aos não beneficiários. Em consonância com essa possibilidade, verificaram-se, pela análise descritiva, indícios de aumento de renda para o primeiro grupo, uma vez que tais agricultores declararam que o PAA-DS facilita a venda da produção e proporciona bons preços de venda, além de continuarem participando do programa após o primeiro acesso, sendo que eles, em sua maioria, o classificam como bom ou ótimo.

Ainda sobre a questão da renda, destaca-se que Oliveira (2011) também não encontrou diferença estatisticamente significativa para essa variável entre os beneficiários e não beneficiários do PAA-Leite em Quixeramobim, no Estado do Ceará, embora o índice de qualidade de vida apresentado pela autora tenha sido maior para o primeiro grupo. Por outro lado, Magalhães \& Soares (2007) e Sobreira (2014) encontraram impacto significativamente positivo para os beneficiários, no que tange à renda da produção agrícola, para o PAA-Leite em diversos estados brasileiros e o PAA para a apicultura no Ceará, respectivamente.

Por outro lado, diferentemente do encontrado por Sobreira (2014), a variável de resposta referente ao número de trabalhadores envolvidos na atividade produtiva foi estatisticamente diferente entre os grupos tanto pela estatística-t quanto pelo p-valor. Dessa forma, enquanto na média, os beneficiários do PAA-DS em Ponte Nova utilizaram em 2015 dois trabalhadores na agricultura, para os não beneficiários, tal valor foi de um trabalhador.

Tal resultado era esperado, já que, como os beneficiários do PAA-DS tendem a aumentar a produção para atenderem à maior demanda proporcionada pelo programa, eles acabam por envolver mais mão de obra na atividade produtiva. Destaca-se que o teste de médias para tal variável na análise descritiva já havia apontado diferença estatisticamente significativa entre os grupos no que tange ao número de trabalhadores envolvidos na atividade agrícola.

Em suma, apesar do resultado inesperado para a variável renda, a significância estatística da diferença entre o número de trabalhadores envolvidos na produção apoiada pelos resultados da análise descritiva de aumento das vendas, melhores preços e classificação satisfatória do PAA-DS por parte dos seus beneficiários indica que o programa foi capaz de melhorar a situação no que tange à produção e criação de mercado para os agricultores no município de Ponte Nova no ano de 2015.

\section{Conclusões}

Em relação à caracterização dos agricultores entrevistados, não se notaram, de maneira geral, diferenças expressivas nas variáveis socioeconômicas e de produção entre os grupos de beneficiários e não beneficiários do PAA-DS.

Quanto à probabilidade de participação no PAA-DS, a única variável estatisticamente significativa foi a participação no programa anterior a 2015, indicando satisfação dos beneficiários com a política implementada, já que continuaram participando dela. Além disso, tal resultado mostra que uma vez acostumado com os procedimentos necessários para participar do programa, o agricultor tende a continuar acessando-o.

No que diz respeito à hipótese levantada, ela foi confirmada parcialmente, já que o procedimento do PSM revelou impacto significativo do PAA-DS para os beneficiários apenas no que tange ao aumento do número de trabalhadores envolvidos na atividade agrícola, não ocorrendo o mesmo para a renda mensal. O resultado inesperado para essa última variável está mais associado à limitação dos dados, uma vez que a renda mensal foi 
coletada por meio de faixas de renda, do que à inexistência de aumento de renda para os beneficiários. Embasando essa possibilidade, verificaram-se, pela análise descritiva, indícios de aumento de renda para tal grupo, já que esses agricultores declararam que o PAA-DS facilita a venda da produção e proporciona bons preços de venda, além de continuarem participando do programa após o primeiro acesso, sendo que eles, em sua maioria, o classificaram como bom ou ótimo.

Portanto, o programa cumpriu o seu objetivo de inclusão social no campo por meio do fortalecimento da agricultura familiar em Ponte Nova-MG no ano de 2015. Entretanto, há espaço para melhorias, uma vez que grande parte dos não beneficiários manifestaram interesse em participar do PAA-DS, não o fazendo por falta de oportunidade e dificuldades operacionais vinculadas à participação no programa. Dessa forma, sugere-se para os formuladores e executores de tal política que, dentro do possível, sejam diminuídas as exigências burocráticas e operacionais para a participação no PAA-DS, além de promoverem uma estratégia de aproximação entre os agricultores familiares e as entidades responsáveis pelo programa, de forma a aumentar a parceria e o auxílio entre tais agentes. No entanto, é importante destacar que a drástica redução no volume de recursos federais destinados ao PAA a partir de 2016, torna-se fator complicador para a realização de aprimoramentos ao programa.

Para trabalhos futuros, sugere-se a obtenção da variável renda por meio de declaração de imposto de renda, notas fiscais ou outra maneira formal aplicável, uma vez que o levantamento por meio de entrevista mostrou-se inadequado e pouco preciso, constituindose na principal limitação do estudo. Adicionalmente, seria interessante também quantificar o impacto do PAA na alteração da qualidade de vida do agricultor por meio de outros indicadores, por exemplo, saúde, escolaridade e acesso a bens e serviços diversos.

\section{Referências bibliográficas}

Agapto, J. P., Borsatto, R. S., Esquerdo, V. D. S., \& Bergamasco, S. M. P. P. (2012). Avaliação do Programa de Aquisição de Alimentos (PAA) em Campina do Monte Alegre, Estado de São Paulo, a partir da percepção dos agricultores. Informações Econômicas, 42(2), 13-21.

Ala-harja, M., \& Helgason, S. (2000). Em direção às melhores práticas de avaliação. Revista do Serviço Público, 51(4), 5-60.

Almeida, L. M. M. C., Ferrante, V. L. S. B., \& Paulillo, L. F. (2010). Rede de segurança alimentar de forte coesão social, a partir do Programa de Aquisição de Alimentos (PAA) no município de Araraquara SP. Organizações Rurais \& Agroindustriais, 12(3), 370-385.

Bastos, R. C. (2017). Avaliação da efetividade do projeto de aquisição de gêneros alimentícios da agricultura familiar no município de Coimbra, MG (Dissertação de mestrado). Universidade Federal de Viçosa, Viçosa.

Bebbington, A., Abramovay, R., \& Chiriboga, M. (2008). Social movements and the dynamics of rural territorial development in Latin America. World Development, 36(12), 2874-2887.

Becker, S. O., \& Ichino, A. (2002). Estimation of average treatment effects based on propensity score. The Stata Journal, 2(4), 358-377.

Bernardoni, D. L., Souza, M. C., \& Peixe, B. C. S. (2008). Fortalecimento da função avaliação de políticas públicas: estudo de caso do processo de avaliação da política de emprego e renda da secretaria de estado do trabalho, emprego e promoção social do Paraná. In B. C. S. Peixe, C. M. A. T. Hilgemberg, G. A. Melatti, G. R. F. Bertolini \& H. Machado (Orgs.), Gestão de políticas públicas no Paraná: coletânea de estudos (pp. 381-393). Curitiba: Progressiva.

Biekart, K. (2005). Seven thesis on Latin American social movements and political change: a tribute to Andre Gunder Frank (1929-2005). European Review of Latin American and Caribbean Studies, 79, 8594.

Brasil. Ministério do Desenvolvimento Social - MDS. (2018). Programa de Aquisição de Alimentos (PAA). Brasília: MDS. Recuperado em 15 de novembro de 2018, de http://mds.gov.br/assuntos/segurancaalimentar/programa-de-aquisicao-de-alimentos-paa

Camargo, R. A. L., Baccarin, J. G., \& Silva, D. B. P. (2013). O papel do Programa de Aquisição de Alimentos (PAA) e do Programa Nacional de Alimentação Escolar (PNAE) no fortalecimento da agricultura familiar e promoção da segurança alimentar. Temas de Administração Pública, 8(2), p. x$x \mathrm{x}$. 
Cirino, J. F., \& Silva, S. V. M. (2017). Determinantes para cumprimento do prazo de projetos do Programa de Aquisição de Alimentos - Doação Simultânea em Minas Gerais. Revista de Economia e Sociologia Rural, 55(2), 247-266.

Cohen, E., \& Martínez, R. (2006). Manual de formulación, evaluación y monitoreo de proyectos sociales (169 p.). Santiago, Chile: Divisão de Desenvolvimento Social da Comissão Econômica para a América Latina e o Caribe (CEPAL).

Cotta, T. C. (1998). Metodologias de avaliação de programas e projetos sociais: análise de resultados e de impacto. Revista do Serviço Público, 49(2), 103-124.

Cyntrão, F. M. C. (2008). Programa de aquisição de alimentos (PAA): uma comparação entre dois Estados do Brasil (Dissertação de mestrado). Faculdade de Agronomia e Medicina Veterinária, Universidade de Brasília, Brasília.

Delgado, G. C., Conceição, J. C. P., \& Oliveira, J. J. (2005). Avaliação do programa de aquisição de alimentos da agricultura familiar (PAA) (IPEA, Texto para discussão, No. 1145). Brasília: IPEA.

Dias, T. F., \& Rocha, L. A. (2014). O Programa de Aquisição de Alimentos da Agricultura Familiar (PAA) e seus efeitos nos municípios do Rio Grande do Norte - 2005 a 2011. Administração Pública e Gestão Social, 7(1), 16-25.

Doretto, M., \& Michellon, E. (2007). Avaliação dos impactos econômicos, sociais e culturais do Programa de Aquisição de Alimentos no Paraná. Sociedade e Desenvolvimento Rural, 1(1), p. X-XX.

Duarte, G. B., Sampaio, B., \& Sampaio, Y. (2009). Programa Bolsa Família: impacto das transferências sobre os gastos com alimentos em famílias rurais. Revista de Economia e Sociologia Rural, 47(4), 903 918.

Favero, L. P., Belfiore, P., Takamatsu, R. T., \& Suzart, J. (2014). Métodos quantitativos com Stata (248 p). Rio de Janeiro: Campus-Elsevier.

Grisa, C., Kato, K. Y. M., Flexor, G. G., \& Zimmermann, S. A. (2017). Capacidades estatais para o desenvolvimento rural no Brasil: análise das políticas públicas para a agricultura familiar. Society and Culture, 20(1), p. x-xx.

Gujarati, N. D., \& Porter, D. C. (2011). Econometria básica (5. ed., 902 p.). Porto Alegre: Bookman, 2011.

Instituto Brasileiro de Geografia e Estatística - IBGE. (2018). Mapas. Recuperado em 15 de março de 2018, de http://mapas.ibge.gov.br

Khandker, S., Koolwal, G., \& Samad, H. (2010). Handbook in impact evaluation: quantitative methods and practices. Washington: The International Bank for Reconstruction and Development, The World Bank.

Libanio, C. L. S. (2018). Avaliação de impacto do Programa de Aquisição de Alimentos no município de Ponte Nova, MG (Dissertação de mestrado). Departamento de Economia, Universidade Federal de Viçosa, Viçosa.

Lopes, D. E., \& Almeida, R. A. (2012). Avaliação do Programa de Aquisição de Alimentos (PAA) e do Programa Nacional de Alimentação Escolar (PNAE) em Castilho-SP e em Andradina-SP. Revista Pegada, 13(1), p.x-xx.

Magalhães, A. M., \& Soares, A. (2007). Os impactos do PAA-Leite sobre o preço, a produção e a renda da pecuária leiteira. In J. Vaitsman \& R. Paes-Sousa (Orgs.), Avaliação de políticas e programas (pp. 143198). Brasília: MDS.

Magalhães, A. M., Silveira Neto, R., Dias, F. M., \& Barros, A. R. (2006). A experiência recente do PRONAF em Pernambuco: uma análise por meio de propensity score. Economia Aplicada, 10(1), 57-74.

Maia, G. S., Khan, A. S., \& Sousa, E. P. (2013). Avaliação do impacto do Programa de Reforma Agrária Federal no Ceará: um estudo de caso. Economia Aplicada, 17(3), 379-398.

Martins, S. P., \& Cavalcanti, L. I. (2007). Avaliação do impacto da execução do PAA no Estado do Rio Grande do Norte. Sociedade e Desenvolvimento Rural, 1(1), 1-30.

Oliveira, L. A. S. (2011). Políticas públicas e estratégia sustentável de combate à fome: o caso do PAA-Leite no município de Quixeramobim Ceará (Dissertação de mestrado). Centro de Ciências Agrárias, Universidade Federal do Ceará, Fortaleza.

Oliveira, L. G. (2015). Avaliação do Programa de Aquisição de Alimentos (PAA) e do Programa Nacional de Alimentação Escolar (PNAE) da agricultura familiar: estudo de caso na microrregião de Ubá-MG (Dissertação de mestrado). Universidade Federal de São Carlos, São Carlos.

Organização das Nações Unidas - ONU. (2009). Manual de planificación, seguimiento y evaluación de los resultados de desarrollo. New York: Programa de las Naciones Unidas para el Desarrollo. 
Reardon, T., Berdegué, J., \& Escobar, G. (2001). Rural nonfarm employment and incomes in Latin America: overview and policy implications. World Development, 29(3), 395-410.

Resende, A. C. C., \& Oliveira, A. M. H. C. (2008). Avaliando resultados de um programa de transferência de renda: o impacto do Bolsa-Escola sobre os gastos das famílias brasileiras. Estudos Econômicos, $38(2), 235-265$.

Rocha, A. G. P., Cerqueira, P. S., \& Coelho, V. P. (2007). Um panorama do Programa de Aquisição de Alimentos no Estado da Bahia: estudos de caso em Boa Vista do Tupim, Tapiramutá e Vitória da Conquista. Sociedade e Desenvolvimento Rural, 1(1), p. xx-x.

Rosenbaum, P. R., \& Rubin, D. B. (1983). The Central role of the propensity score in observational studies for causal effects. Biometrika, 70(1), 41-55.

Rossi, F. R. (2012). O programa de Aquisição de Alimentos (PAA) da agricultura familiar no município de São Carlos: impactos socioeconômicos nos agricultores familiares beneficiários (Dissertação de mestrado). Universidade Federal de São Carlos, São Carlos.

Santos, A. R., Vieira, N. S., Ferreira, P. S., \& Castro, T. T. S. (2012). Agricultura familiar e segurança alimentar e nutricional: análise dos resultados do Programa de Aquisição de Alimentos (PAA Doação Simultânea) nos Estados da Bahia e Minas Gerais. Cadernos Gestão Social, 3(1), 9-24.

Secretaria de Avaliação e Gestão da Informação - SAGI. (2018). PAA Data. Recuperado em 15 de março de 2018, de https://aplicacoes.mds.gov.br/sagi/paa/visi_paa_geral/pg_principal.php?url=abertura

Silva, J. G. (2002). Local sustainable development, globalization and agricultural restructuring in underdeveloped countries. International Journal of Sociology of Agriculture and Food, 10(1), 33-39.

Simão, G. L. (2014). Capital social e desenvolvimento local: uma análise do Programa de Aquisição de Alimentos (PAA) na Zona da Mata de Minas Gerais (Dissertação de mestrado). Universidade Federal de Viçosa, Viçosa.

Sobreira, D. B. (2014). Avaliação dos impactos do Programa de Aquisição de Alimentos (PAA) no estado do Ceará: o caso do mel (Dissertação de mestrado). Centro de Ciências Agrárias, Universidade Federal do Ceará, Fortaleza. 


\section{Erratum}

No artigo "Avaliação de impacto do programa de aquisição de alimentos modalidade doação simultânea em Ponte Nova-MG", com número de DOI https://doi.org/10.1590/18069479.2020.195705, publicado no periódico Revista de Economia e Sociologia Rural, vol. 58, no. 2, e195705:

Onde se lia:

Jader Fernandes Cirino, Cínthia Lopes Saliba Libânio

Leia-se:

Cínthia Lopes Saliba Libânio, Jader Fernandes Cirino 